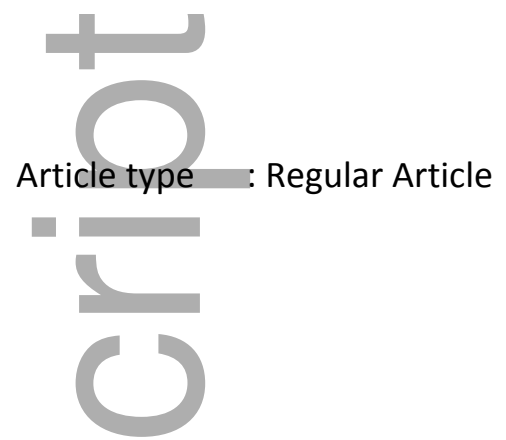

\title{
Body Mass Index and vigorous physical activity in children and adolescents: an international cross-sectional study
}

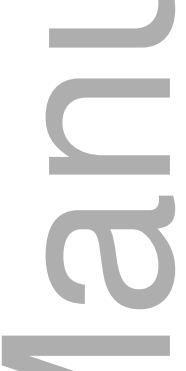

\section{Short Title: Vigorous Physical Activity and BMI in children}

Irene Braithwaite ${ }^{1}$, Alistair W Stewart ${ }^{2}$, Robert J Hancox ${ }^{3}$, Rinki Murphy ${ }^{4}$, Clare R. Wall ${ }^{5}$, Richard Beasley ${ }^{1}$, Edwin A Mitchell ${ }^{6}$, and the ISAAC Phase Three Study Group ${ }^{7}$

${ }^{1}$ Medical Research Institute of New Zealand, Wellington, New Zealand. ${ }^{2}$ School of Population Health, The University of Auckland, Auckland, New Zealand. ${ }^{3}$ Department of Preventive \& Social Medicine, Dunedin School of Medicine, University of Otago, Dunedin, New Zealand. ${ }^{4}$ Department of Medicine, Faculty of Medicine and Health Sciences, The University of Auckland, Auckland, New Zealand. ${ }^{5}$ Discipline of Nutrition and Dietetics, Faculty of Medicine and Health Sciences, The University of Auckland, Auckland, New Zealand. ${ }^{6}$ Department of Paediatrics: Child and Youth Health, Faculty of Medicine and Health Sciences, The University of Auckland, Auckland, New Zealand ${ }^{7}$ Full listing of study group in the acknowledgements

\section{Correspondence to:}

This is the author manuscript accepted for publication and has undergone full peer review but has not been through the copyediting, typesetting, pagination and proofreading process, which may lead to differences between this version and the $\underline{\text { Version of Record. Please cite this article as doi: 10.1111/apa.13903 }}$

This article is protected by copyright. All rights reserved 
Dr Irene Braithwaite

Medical Research Institute of New Zealand

Private Bag 7902, Wellington 6242

New Zealand

Email: irene.braithwaite@mrinz.ac.nz

Telephone: +64 48050245

Word Count: Abstract 199, manuscript 2,621. Refs 26, figures 3, tables 1

\section{ABSTRACT:}

Aim: To examine the relationship between reported vigorous physical activity (VPA) and body mass index (BMI) in children (6-7 years) and adolescents (13-14 years).

Methods: In the International Study of Asthma and Allergies in Childhood Phase Three, 75,895 children's parents and 199,502 adolescents answered questions relating to VPA, height and weight. The association between VPA and BMI was analysed using general linear models, adjusting for country gross national index.

Results: Compared to children who undertook no VPA, those in the infrequent group (once or twice per week) and those in the frequent group (three or more times per week) had mean $\left(95 \% \mathrm{Cl}\right.$ ) BMI values $0.07 \mathrm{~kg} / \mathrm{m}^{2}$ (0.03 to 0.11 ) and $0.09 \mathrm{~kg} / \mathrm{m}^{2}$ (0.03 to 0.15$)$ greater respectively ( $P=0.001)$. Compared to adolescents reporting no VPA, those in the infrequent group had a BMI $0.19 \mathrm{~kg} / \mathrm{m}^{2}(0.15$ to 0.23$)$ greater while those in the frequent group had a BMI $0.01 \mathrm{~kg} / \mathrm{m}^{2}(-0.03$ to 0.05$)$ greater $(P<0.0001)$.

Conclusion: Reported VPA is not associated with lower BMI among children and adolescents. Investigation of VPA and BMI may be best undertaken in conjunction with other variables in the energy expenditure equation. A focus on VPA alone may be an inefficient way to manage BMI.

Key Words: body mass index, vigorous physical activity, child, adolescent, obesity

\section{Key notes:}

This article is protected by copyright. All rights reserved 
- Vigorous physical activity is considered to be a modifiable component of the energy consumption and expenditure equation which results in weight maintenance or weight change in individuals.

Increasing levels of reported vigorous physical activity were associated with a higher Body Mass Index (BMI) in children and adolescents.

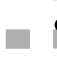

A focus on vigorous physical activity alone may be an inefficient way to manage BMI in children and adolescents.

\section{INTRODUCTION:}

The rising prevalence of childhood obesity since the 1980's has been marked(1-4). This problem has been identified in low and middle income countries as well as affluent countries(5-7). In 2004 it was estimated that over 170 million children worldwide under the age of 18 were overweight(8). Obesity tracks from childhood into adulthood and results in an increased risk for diabetes and cardiovascular disease, stroke, and several cancers $(9,10)$. This has motivated the development of the World Health Organisation (WHO) Commission in Ending Childhood Obesity $(11,12)$.

The causes of obesity are multifactorial(13). Dietary and physical activity patterns are considered to be important factors in the development of overweight and obesity as they are modifiable components of the energy consumption and expenditure equation that results in weight maintenance or weight change of individuals.

Studies investigating associations between children's physical activity levels and body mass index (BMI) have produced mixed results. In one instance, increasing levels of vigorous exercise were associated with increased fitness and leanness in adolescents(14), while in another study low exercise levels and high sedentary levels were associated with increased risk of overweight in boys while sedentary behaviours seemed more important than physical exercise with respect to overweight status in girls(15). Interventional studies to reduce overweight and obesity in children have tended to include both nutritional and exercise interventions(16), although one study reported that exercise alone had no effect on BMI despite improving fitness levels(17).

The International Study of Asthma and Allergies in Childhood (ISAAC) Phase Three is a multi-national multi-centre study that has previously collected data on heights This article is protected by copyright. All rights reserved 
and weights of children aged 6-7 years and 13-14 years as well as reported weekly episodes of vigorous physical activity (VPA)(18). Although originally designed to measure time trends in the prevalence, severity, and risk factors and the development of asthma and allergies, ISAAC Phase Three has provided us with the opportunity to investigate the relationship between reported VPA and BMI across a range of countries in both children and adolescents

This study is an analysis of the reported frequency of VPA in children and adolescents, and its association with BMI. We hypothesised that children and adolescents reporting higher levels of VPA would have lower BMI values.

\section{PATIENTS AND METHODS:}

ISAAC is a multicentre, multi-country, multiphase, cross-sectional study investigating the prevalence of the symptoms of asthma, rhinoconjunctivitis and eczema, and the role of risk factors, as previously described(18). ISAAC Phase Three used a standardised core questionnaire on symptoms of asthma, rhinoconjunctivitis and eczema, and included an optional environmental questionnaire (EQ) to collect potential risk factor data including participant height, weight, and VPA. The EQ was translated from English into the local language for all centres, and back-translated to English after completion using study specific translation guidelines(18). The adolescents self-completed their questionnaires and parents or guardians completed questionnaires for the children. Phase Three was undertaken between 2001 and 2003. The questionnaires are on the ISAAC website and can be accessed at the following url: http://isaac.auckland.ac.nz. As this is a secondary analysis of preexisting data, ethics approval was not sought for this study.

\section{Main outcome variable - Body Mass Index:}

Height and weight were reported by the parents of the children, and were selfreported by adolescents. In some centres, each subject's height and weight were measured objectively, although there were no standardised or specific instructions for doing this. BMI was calculated (weight $(\mathrm{kg}) /$ height $\left.(\mathrm{m})^{2}\right)$.

\section{Explanatory variables:}

The frequency of reported VPA undertaken by study participants was assessed using the following question: "How many times a week do you (does your child) engage in vigorous physical activity long enough to make you (him/her) breathe hard?" 
Participants categorised their answers as 'Never or occasionally' (no VPA), 'Once or twice per week' (infrequent VPA) or 'Three or more times per week' (frequent VPA).

Country Gross National Income (GNI) was included in the model to identify if this influenced any associations between reported VPA and BMI(13). This was based on the 2006 World Bank categories of high-, high middle-, low middle-, and lowincome countries, dichotomised into high income (high- plus high middle-income) and low income (low middle- plus low-income) categories.

\section{Participants:}

Complete data for height, weight, and reported VPA variables were submitted for 214,706 children (73 centres in 32 countries) and for 362,091 adolescents (122 centres in 53 countries).

Only centres that provided $>70 \%$ data for reported VPA were included in our analyses. Within these centres, individuals without complete age, sex, height, weight, or VPA data were excluded.

\section{Data cleaning:}

To preserve as much BMI data as possible, but also to eliminate likely erroneous data, we applied the following thresholds:

For children in each centre, those in the top and bottom $0.5 \%$ of weights and heights, and those with heights less than 1.0 metre were excluded. Children with BMI less than $9 \mathrm{~kg} / \mathrm{m}^{2}$ and greater than $40 \mathrm{~kg} / \mathrm{m}^{2}$ were excluded.

For adolescents in each centre, those in the top and bottom $0.5 \%$ of weights and heights, and those with heights less than 1.25 metres were excluded. Adolescents with BMI less than $10 \mathrm{~kg} / \mathrm{m}^{2}$ and greater than $45 \mathrm{~kg} / \mathrm{m}^{2}$ were excluded.

Following sequential application of the exclusion and data cleaning criteria described above, 75,895 children ( 31 centres/18 countries) and 199,502 adolescents (74 centres/36 countries) were included in the final analysis (Figure 1). 


\section{Statistical Analysis:}

BMI met normally assumptions in both age groups, and was assessed using a general linear mixed model with centre as a random effect and GNI for each country, the individual's age, sex, measurement type, and reported VPA variable as fixed effects. The BMI reference values reported are the modelled means for the no VPA groups in the children and adolescents respectively.

Further analyses were undertaken separately for children with objectively measured heights and weights due to a statistically significant interaction found between measurement type and VPA, with a slightly different pattern of BMI difference in VPA groups compared to the overall analysis of children's BMls. In adolescents, statistically significant interactions between sex and VPA and GNI and activity were found. However, because the pattern of BMI change between VPA groups was consistent with the overall analysis, sub-analyses were not reported.

SAS (v9.3, SAS Institute, Cary, NC) was used.

\section{RESULTS:}

\section{Reported Vigorous Physical Activity}

For reported VPA in children, 45\% were in the no VPA group, 35\% were in the infrequent VPA group, and $21 \%$ were in the frequent VPA group. The proportion of those who reported frequent VPA ranged from $45 \%$ in Spain to $2 \%$ in Lithuania. (Figure 2a)

For reported VPA in adolescents, 28\% were in the no VPA group, 45\% were in the infrequent VPA group, and 27\% were in the frequent VPA group. The proportion of those who reported frequent VPA ranged from $51 \%$ of adolescents in Canada to $5 \%$ in Lithuania. (Figure 2b).

\section{Associations between reported vigorous physical activity and BMI:}

\section{Children:}

Figure 3a shows the difference in BMI $(\mathrm{kg} / \mathrm{m} 2)$ between children in the no VPA group, and children in the infrequent VPA and frequent VPA groups in each centre. In the analysis using the three separate groups, after controlling for country $\mathrm{GNI}$, centre, 
age, sex, and measurement type, the infrequent VPA group had a BMI $0.07(95 \% \mathrm{Cl}$ 0.03 to 0.11$) \mathrm{kg} / \mathrm{m}^{2}$ greater than the no VPA group and the frequent VPA group had a BMI $0.09(95 \% \mathrm{Cl} 0.03$ to 0.15$) \mathrm{kg} / \mathrm{m}^{2}$ greater than the no VPA group, with an overall $P$ value of 0.001 (Table 1). When data were analysed with objectively measured heights and weights only, the infrequent VPA group had a BMI $0.07(95 \% \mathrm{CI}-0.03$ to $0.03) \mathrm{kg} / \mathrm{m}^{2}$ smaller than the no VPA group and the frequent VPA group had a BMI $0.08(95 \% \mathrm{Cl}-0.02$ to 0.18$) \mathrm{kg} / \mathrm{m}^{2}$ greater than the no VPA group (overall $\mathrm{P}$ value $0.01)$.

\section{Adolescents:}

Figure $3 \mathrm{~b}$ shows the difference in BMI $\left(\mathrm{kg} / \mathrm{m}^{2}\right)$ between adolescents in the no VPA group and those in the infrequent and frequent VPA group in each centre. In the analysis using the three separate groups, after controlling for country GNI, centre, age, sex, measurement type, the infrequent VPA group had a BMI 0.19 (95\%CI 0.15 to 0.23$) \mathrm{kg} / \mathrm{m}^{2}$ greater than the no VPA group, and the BMI of the frequent VPA group was almost the same as the no VPA group (Table 1).

Statistically significant interactions were found between sex and reported VPA activity and GNI and reported VPA, but when these sub-groups were analysed separately, the same pattern of highest BMI in the infrequent VPA group and little difference between the BMls of those in the frequent VPA and no VPA groups remained.

\section{DISCUSSION:}

Contrary to our hypothesis, infrequent and frequent reported VPA were associated with higher BMI values compared to no VPA in children, although the difference in mean BMI was small. In adolescents, infrequent VPA was associated with higher $B M I$ values than no VPA, while there was no difference in mean BMI between those reporting frequent VPA and those reporting no VPA. In this study frequent VPA (three or more times per week) was reported by $21 \%$ and $27 \%$ of children and adolescents respectively. These findings indicate that most children do not achieve the levels of exercise recommended by the WHO (daily moderate to vigorous physical activity, mostly aerobic, for a minimum of 60 minutes)(19).

The public health relevance of these findings are important, as they suggest that VPA alone is not the major determinant of BMI in children and adolescents, and that this is 
the case across a range of countries with different cultures and incomes. Our finding of slightly higher mean BMI values among children in the infrequent and frequent VPA groups $\left(+0.07 \mathrm{~kg} / \mathrm{m}^{2}\right.$ and $+0.09 \mathrm{~kg} / \mathrm{m}^{2}$ respectively), compared to the no VPA group, while statistically significant, is of uncertain clinical significance, as are the results after restricting the analysis to those children with objectively measured heights and weights. The pattern of BMI change in the objectively measured group was inconsistent $\left(-0.07 \mathrm{~kg} / \mathrm{m}^{2}\right.$ and $+0.08 \mathrm{~kg} / \mathrm{m}^{2}$ in the infrequent and frequent VPA groups respectively), possibly due to a reduction in power through analysing the smaller sub-sample. Adolescents in the infrequent group had a higher BMI $\left(+0.19 \mathrm{~kg} / \mathrm{m}^{2}\right)$, while those in the frequent group had a very similar BMI $\left(+0.01 \mathrm{~kg} / \mathrm{m}^{2}\right)$ compared to those reporting no VPA. In the most direct comparison to this study, Janssen and colleagues found that self-reported physical activity was associated in a dose response manner with lower BMI (based on self-reported heights and weights) in 136,000 youths aged between 10 and 16 years of age in 29 out of 34 countries(20), 9 countries of which are in common with our study. Possible reasons for the difference between Janssen's findings and our own include the fact that Janssen's group ranged from 10 years of age to 16 while our participants were concentrated at 13 and 14 years of age, a time when BMI and body composition can change rapidly in both males and females(21). In one study investigating VPA and body fatness in adolescents, it was found that those who engaged in large amounts of VPA were more likely to be fit and lean(13). A study of the effects of physical activity in 6-10 year old children found that girls significantly reduced waist circumference, skinfold measurements and fat free mass but not BMI, while in boys there were significant reductions in only z-BMI and fat free mass(22). While other studies have investigated the associations between VPA and BMI, this has often been in the context of additional factors such as sedentary activities $(14,23)$, or in the context of multifactorial interventions(15).

It is possible that in both age groups, those engaging in higher levels of VPA have a higher muscle mass than those reporting no VPA, resulting in a slightly higher BMI in the infrequent and frequent VPA groups. There may also be a degree of reverse causation where those individuals with higher BMls are already engaging in higher amounts of VPA in order to moderate their weight. These findings are consistent with the concept that in the context of overall energy intake and expenditure, VPA alone may in fact have only a limited influence on $\mathrm{BMI}$, and is perhaps more a moderator of the trajectory of weight gain(24). Additionally, in the initial phases of 
exercise programmes, high levels of activity can result in weight loss, but there is often a longer term compensatory increase in food intake, and such weight losses are generally not sustained, which may also be reflected in these results(25).

The main strength of this study is the large number of participants who provided data (75,895 children and 199,502 adolescents) even after elimination of centres with response rates of $<70 \%$ to the VPA questions. It is possible that non-responders and the exclusion of centres with $<70 \%$ response rates may have led to some bias in our results, the degree of which is uncertain. As the initial study was investigating putative risk factors for asthma, there is no reason to suspect that non-responders and those with data excluded will differ substantively with respect to VPA and BMI from those included. Data was included from a large number of participants from centres in numerous countries with quite different levels of income and cultures and it is likely that the findings are generalisable to many populations. As with all studies of this kind, there are a number of other methodological limitations to take into account which can be categorised into three broad areas; the definition and measurement of VPA, use of BMI as the primary outcome variable, and the use of other covariates. With respect to VPA, the definition in the questionnaire of is one that required participants to 'breathe hard'. Exercise that 'makes you breathe hard' is likely to be influenced by BMI as much as the nature of the activity, thus those with higher BMIs may respond positively to this question, while those with lower BMls who did the same activity without breathing hard may not have counted this as VPA, skewing the results towards higher levels of VPA in participants with a higher BMI. The retrospective recall of VPA is subject to recall bias, in that participants with higher BMIs may have over-reported their VPA, which may also have skewed the results towards higher levels of VPA in participants with higher BMls. Accelerometers that would have allowed objective assessment of activity frequency and intensity were not used in this study. With respect to BMI, heights and weights were reported by the parents of children and by the adolescents themselves. Past research has shown that differences between actual weight and self-reported weight can be greater for obese children and adolescents compared with non-obese(26), which is likely to have skewed results in the direction we have found. We were limited to the use of $\mathrm{BMI}$ as the outcome measure for this study rather than objective measures of fat mass or body composition, as only information on heights and weights were collected in this study. Different measures of body composition, such as underwater weighing, air displacement plethysmography or Fat Mass Indexes may have shown a different

This article is protected by copyright. All rights reserved 
pattern of association with VPA. However, calculation of BMI from measured or reported heights and weights is a cost effective way to assess large cross-sectional samples such as the one we are reporting. Finally, we have not adjusted for confounding variables such as dietary intake which forms the second arm of the important energy equation associated with overweight and obesity, and it is difficult to predict how this may have affected our findings.

\section{Conclusions:}

This study has demonstrated that reported vigorous physical activity is not associated with lower BMI among children and adolescents. Investigation of VPA and $\mathrm{BMI}$ is best undertaken in conjunction with other variables in the energy expenditure equation. This highlights the multifactorial nature of overweight and obesity in children and adolescents, and the likelihood that VPA alone may be an inefficient way to address overweight and obesity in this age group.

\section{CONFLICTS OF INTEREST STATEMENT}

All authors declare that they have no conflicts of interest relating to the development of this article.

\section{ACKNOWLEDGEMENTS AND OTHER STATEMENTS:}

Correspondence: Irene Braithwaite, MBCHB, Medical Research Institute of New Zealand, Private Bag 7902, Wellington 6242, New Zealand

Funding / Support: This work was supported by Cure-Kids New Zealand through a grant to Professor E Mitchell and Dr I Braithwaite. Cure Kids New Zealand had no role or influence in design and conduct of the study; collection, management, analysis, and interpretation of the data; and preparation, review, or approval of the manuscript; and decision to submit the manuscript for publication.

ISAAC Phase Three: We are grateful to the children and parents who participated in the ISAAC Phase Three Study. We are also grateful to the ISAAC Steering Committee, the ISAAC International Data Centre and ISAAC Phase Three Principal Investigators and Regional and National coordinators as listed below.

This article is protected by copyright. All rights reserved 


\title{
ABBREVIATIONS:
}

\author{
BMI Body mass index \\ GNI Gross National Index
}

ISAAC International Study of Asthma and Allergies in Childhood

VPA Vigorous physical activity

\section{WHO Word Health OrganisationREFERENCES:}

1. Chinn S, Rona RJ. Prevalence and trends in overweight and obesity in three cross sectional studies of British Children, 1974-94. BMJ 2001; 322: 24-6.

2. Strauss RS, Pollack HA. Epidemic increase in childhood overweight, 19861998. JAMA 2001; 286: 2845-8.

3. Tremblay MS, Katzmarzyk PT, Willms JD. Temporal trends in overweight and obesity in Canada, 1981-1996. Int J Obes Relat Metab Disord 2002; 26: 53843.

4. De Onis M, Blössner M, Borghi E. Global prevalence and trends of overweight and obesity among preschool children. Am J Clin Nutr 2010; 92: 1257-64.

5. El Mugamer IT, Ali Zayat AS, Hossain MM, Pugh RN. Diabetes, obesity and hypertension in urban and rural people of bedouin origin in the United Arab Emirates. J Trop Med Hyg 1995; 98: 407-15.

6. Wang Y, Chen HJ, Shaikh S, Mathur P. Is obesity becoming a public health problem in India? Examine the shift from under- to overnutrition problems over time. Obes Rev 2009; 10: 456-74.

7. De Onis M, Blossner M. Prevalence and trends of overweight among preschool children in developing countries. Am J Clin Nutr 2000; 72: 1032-9.

This article is protected by copyright. All rights reserved 
8. Lobstein T, Baur L, Uauy R, Lobstein T. Obesity in children and young people: a crisis in public health. Obes Rev 2004; 5 Suppl 1: 4-104.

9. Franks PW, Hanson RL, Knowler WC, Sievers ML, Bennett PH, Looker HC. Childhood obesity, other cardiovascular risk factors, and premature death. $N$ Engl J Med 2010; 362: 485-93.

10. Sinha R, Fisch G, Teague B, Tamborlane WV, Banyas B, Allen K, Savoye M, Rieger V, Taksali S, Barbetta G, Sherwin RS. Prevalence of impaired glucose tolerance among children and adolescents with marked obesity. $N$ Engl J Med 2002; 346: 802-10.

11. World Health Organisation (WHO). Global action plan for the prevention and control of non-communicable diseases 2013-2020. WHO 2013.

12. World Obesity Federation. World Map of Obesity [Internet]. 2016. Available from: http://www.worldobesity.org/resources/world-map-obesity/

13. Han JC, Lawlor DA, Kimm SYS. Childhood Obesity - 2010 : Progress and Challenges. Lancet 2010; 375: 1737-48.

14. Gutin B, Yin Z, Humphries MC, Barbeau P. Relations of moderate and vigorous physical activity to fitness and fatness in adolescents. Am J Clin Nutr 2005; 81: 746-50.

15. te Velde SJ, Bourdeaudhuij ID, Thorsdottir I, Rasmussen M, Hagströmer M, Klepp K, Brug J. Patterns in sedentary and exercise behaviours and associations with overwight 9-14-year-old boys and girls - a cross-sectional study. BMC Public Health. 2007; 7: 16.

16. Waters E, de Silva-Sanigorski A, Burford BJ, Brown T, Campbell KJ, Gao Y, Armstrong R, Prosser L, Summerbell CD. Intevrentiosn for preventing obesity in children (Review). Cochrane Databse of Systematic Reviews. 2011; Issue2: Art No.:CD001871.

17. DeStefano RA, Caprio S, Fahey JT, Tamborlane WV, Goldberg B. Changes in body composition after a 12-wk aerobic exercise program in obese boys. Pediatric diabetes. 2000; 1(2): 61-5. 
18. Ellwood P, Asher MI, Beasley R, Clayton TO, Stewart AW. The international study of asthma and allergies in childhood (ISAAC): Phase Three rationale and methods. Int J Tuberc Lung Dis 2005; 9: 10-6.

19. World Health Organization. Global recommendations on physical activity for health. WHO 2011.

20. Janssen I, Katzmarzyk PT, Boyce WF, Vereecken C, Mulvihill C, Roberts C, Currie C, Pickett W. Comparison of overweight and obesity prevalence in school-aged youth from 34 countries and their relationships with physical activity and dietary patterns. Obes Rev 2005; 6: 123-32.

21. Daniels SR, Khoury PR, Morrison JA. The utility of body mass index as a measure of body fatness in children and adolescents: differences by race and gender. Pediatrics 1997; 99: 804-7.

22. Lazaar N, Aucouturier J, Ratel S, Rance M, Meyer M, Duché P. Effect of physical activity intervention on body composition in young children: influence of body mass index status and gender. Acta Paediatrica. 2007; 96(9): 1321-5.

23. Andersen RE, Crespo CJ, Bartlett SJ, Cheskin LJ, Pratt M. Relationship of physical activity and television watching with body weight and level of fatness among children: results from the Third National Health and Nutrition Examination Survey. JAMA 1998; 279(12): 938-42.

24. Wilks DC, Besson H, Lindroos AK, Ekelund U. Objectively measured physical activity and obesity prevention in children, adolescents and adults: $A$ systematic review of prospective studies. Obes Rev 2011; 12: e119-e129.

25. Blundell JE, Stubbs RJ, Hughes DA, Whybrow S, King NA. Cross talk between physical activity and appetite control: does physical activity stimulate appetite? Proc Nutr Soc 2003; 62: 651-61.

26. Strauss RS. Comparison of measured and self-reported weight and height in a cross-sectional sample of young adolescents. Int J Obes Relat Metab Disord 1999; 23: 904-8.

This article is protected by copyright. All rights reserved 


\section{TABLES:}

Table 1: Association between reported vigorous physical activity and BMI (+/$\left.\mathrm{kg} / \mathrm{m}^{2}\right)(95 \% \mathrm{Cl})$ of study participants

\begin{tabular}{|c|c|c|c|c|}
\hline 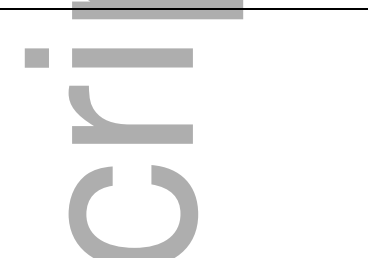 & $\begin{array}{c}\text { No activity } \\
\text { (never or } \\
\text { occasionally) }\end{array}$ & $\begin{array}{c}\text { Infrequent } \\
\text { activity (once } \\
\text { or twice per } \\
\text { week) }\end{array}$ & $\begin{array}{c}\text { Frequent } \\
\text { activity (three } \\
\text { or more times } \\
\text { per week) }\end{array}$ & P Value \\
\hline $\begin{array}{l}\text { Children } \\
(\mathrm{N}=75,895)\end{array}$ & $\mathrm{REF}^{\mathrm{i}}$ & $\begin{array}{l}+0.07 \mathrm{~kg} / \mathrm{m}^{2} \\
(0.03 \text { to } 0.11)\end{array}$ & $\begin{array}{c}+0.09 \mathrm{~kg} / \mathrm{m}^{2} \\
(0.03 \text { to } 0.15)\end{array}$ & 0.001 \\
\hline $\begin{array}{l}\text { Children: objective } \\
\text { height and weight } \\
\text { measures only ( } \mathrm{N}= \\
15,035)\end{array}$ & $\mathrm{REF}^{\mathrm{i}}$ & $\begin{array}{c}-0.07 \mathrm{~kg} / \mathrm{m}^{2} \\
(-0.03 \text { to } 0.03)\end{array}$ & $\begin{array}{c}+0.08 \mathrm{~kg} / \mathrm{m}^{2} \\
(-0.02 \text { to } 0.18)\end{array}$ & 0.01 \\
\hline $\begin{array}{l}\text { Adolescents } \\
(\mathrm{N}=199,502)\end{array}$ & $\mathrm{REF}^{1}$ & $\begin{array}{l}+0.19 \mathrm{~kg} / \mathrm{m}^{2} \\
(0.15 \text { to } 0.23)\end{array}$ & $\begin{array}{c}+0.01 \mathrm{~kg} / \mathrm{m}^{2} \\
(-0.03 \text { to } 0.05)\end{array}$ & $<0.0001$ \\
\hline
\end{tabular}

\section{FIGURE HEADINGS:}

Figure 1: Flow of participants through study. Children are represented in panel (a) and adolescents in panel (b)

Figure 2: The proportion of children and adolescents reporting 'never', 'infrequent' or 'frequent' vigorous physical activity on a weekly basis. Children are shown in panel a) and adolescents are shown in panel b).

Figure 3: The difference in BMI $(\mathrm{kg} / \mathrm{m} 2)$ between children and adolescents who reported no vigorous physical activity and those who reported infrequent or frequent vigorous physical activity on a weekly basis by centre. Children are represented in panel a) and adolescents are represented in panel b). The proportion of participants who reported frequent vigorous physical activity is shown in parentheses after each country. The solid dots represent centres with 
reported heights and measures and the circled dots represent centres that measured heights and weights.

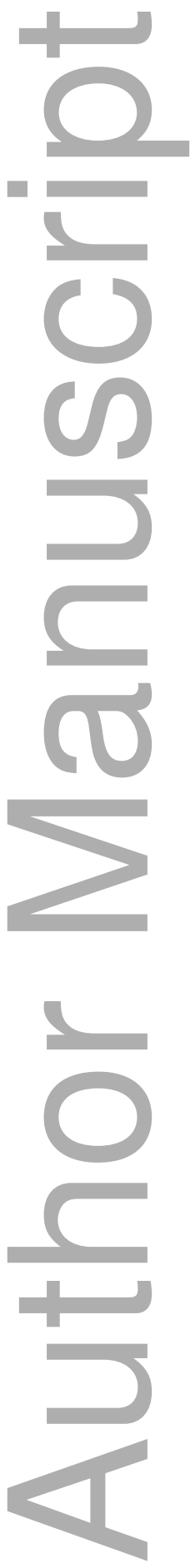

This article is protected by copyright. All rights reserved 
a)

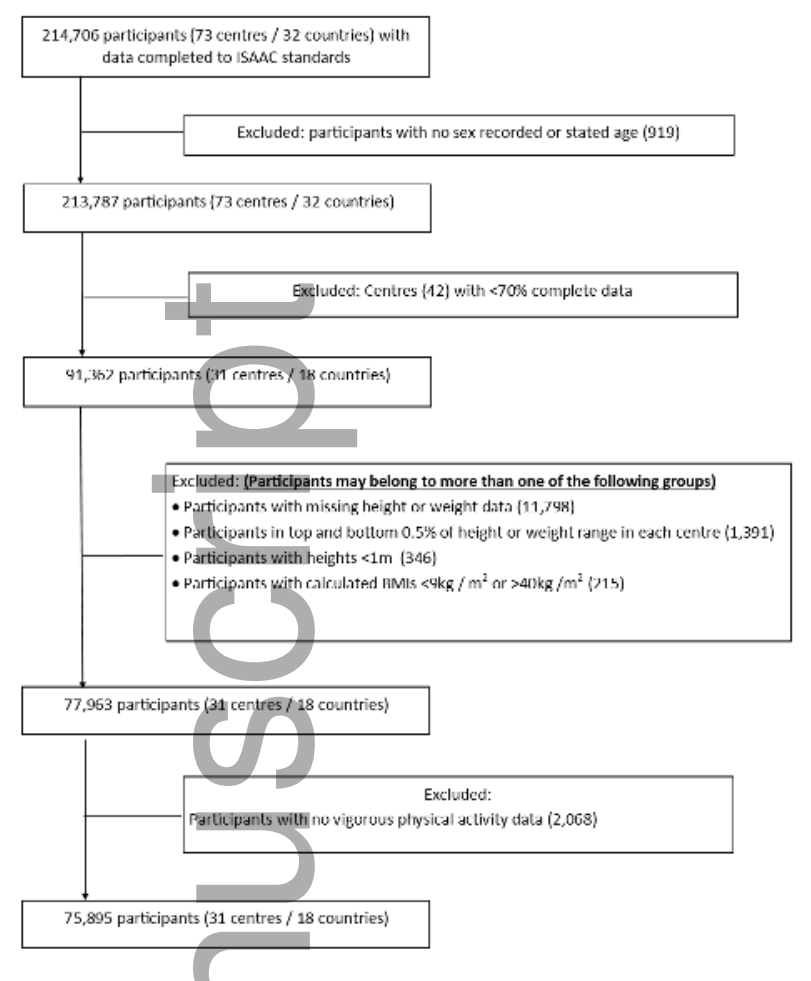

b)

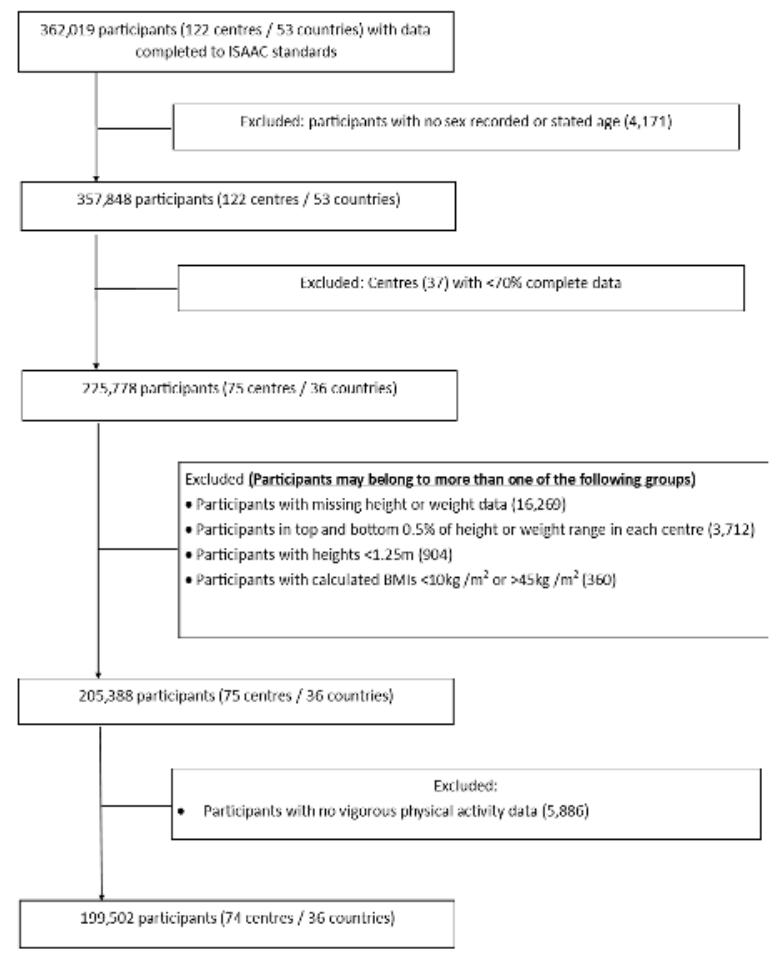

apa_13903_f1.tif

This article is protected by copyright. All rights reserved 
a)

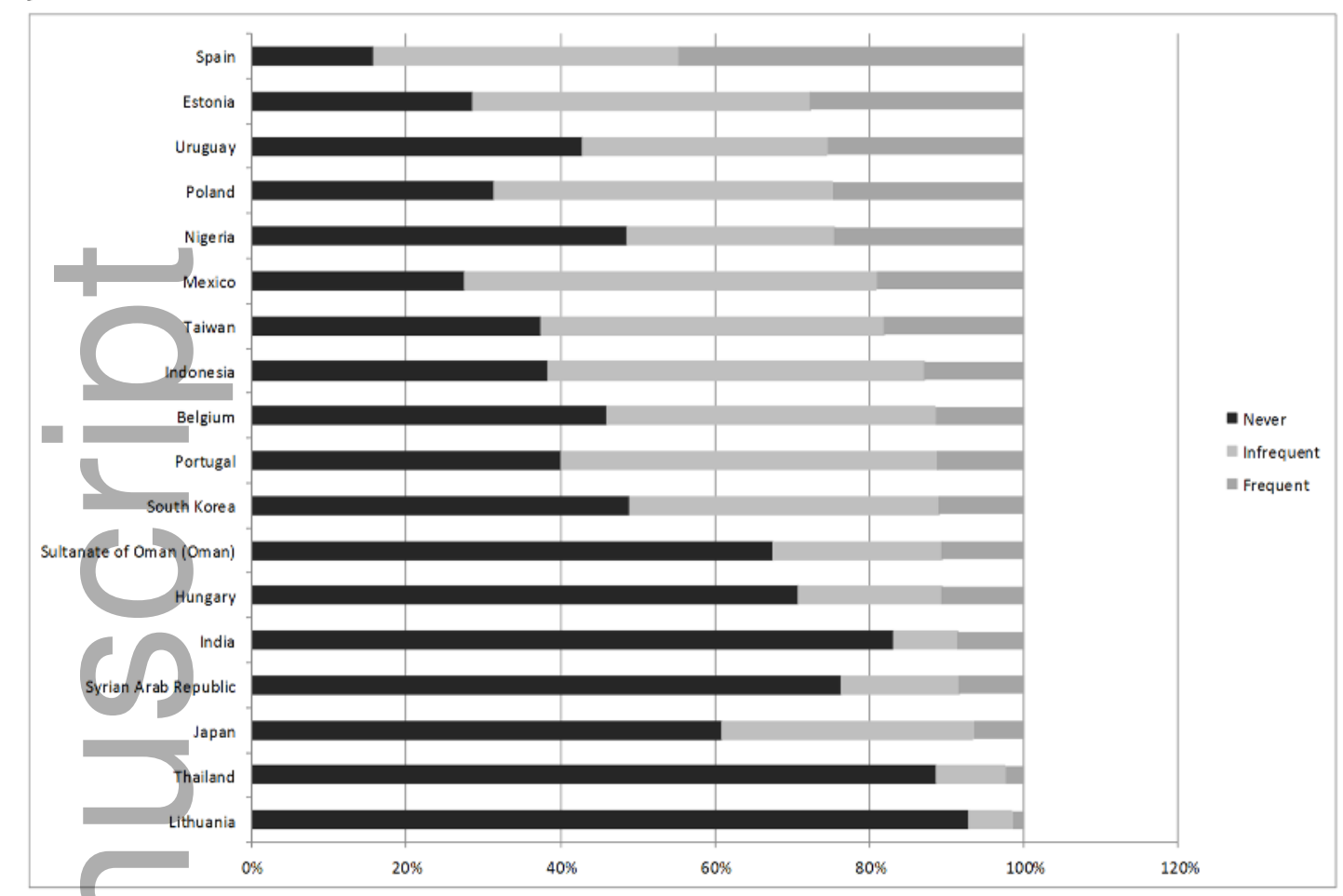

b)

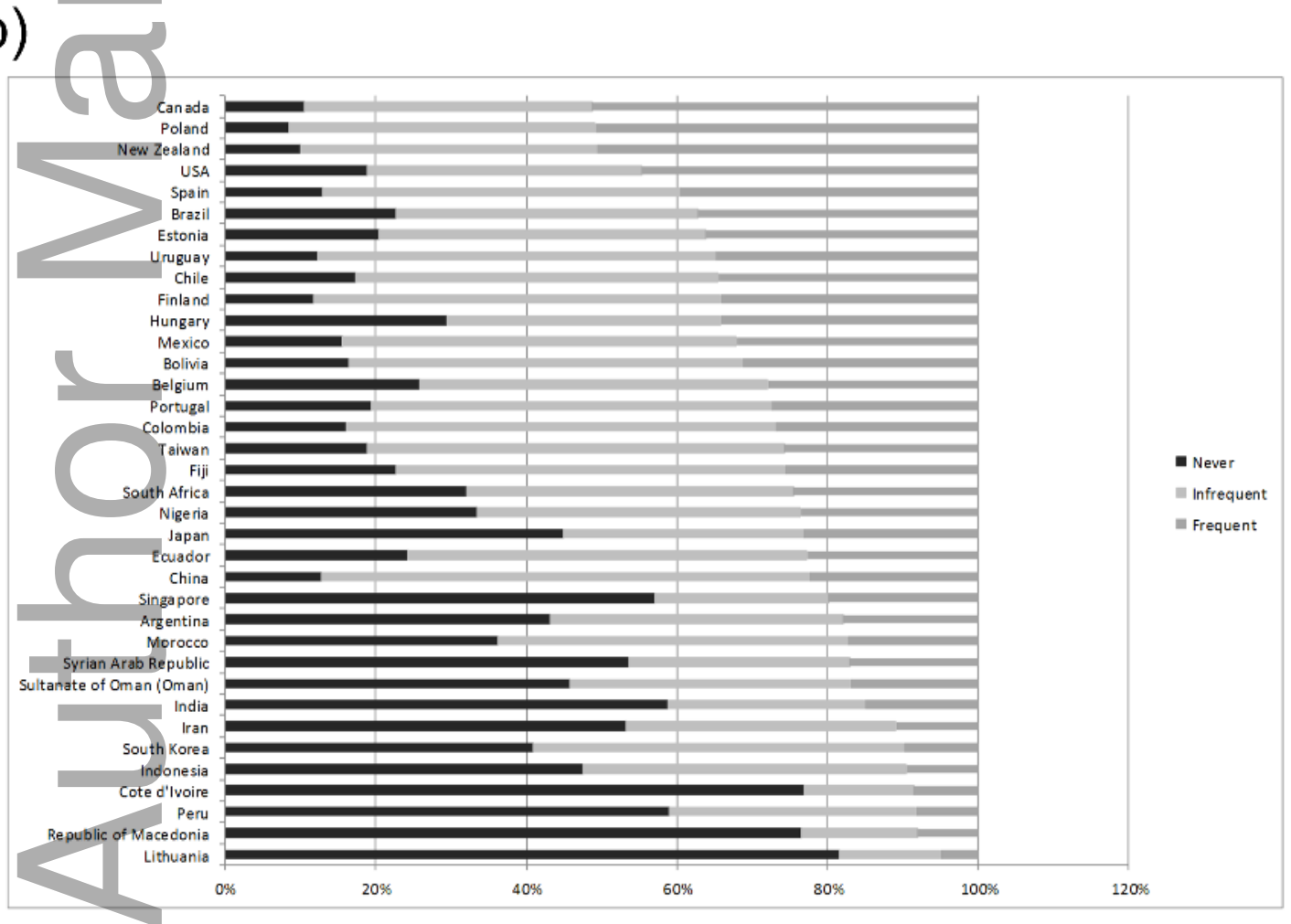

apa_13903_f2.tif

This article is protected by copyright. All rights reserved 
a)

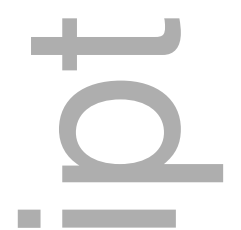

$\square$
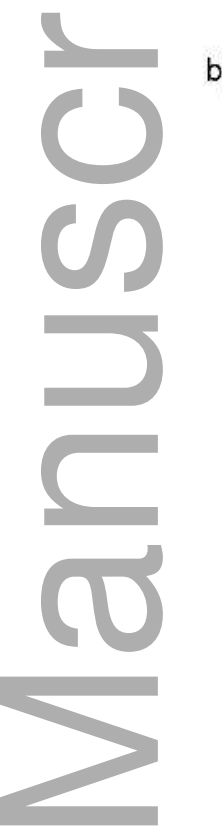

b)

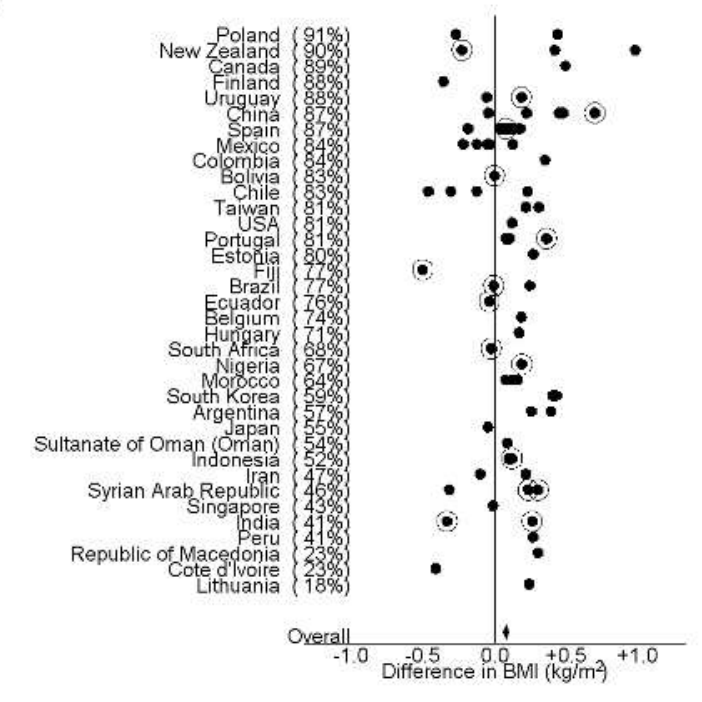

apa_13903_f3.tif 


\section{University Library}

\section{- M I I N E R VA \\ A gateway to Melbourne's research publications}

Minerva Access is the Institutional Repository of The University of Melbourne

\section{Author/s:}

Braithwaite, IE;Stewart, AW;Hancox, RJ;Murphy, R;Wall, CR;Beasley, R;Mitchell, EA;ISAAC

Phase Three Study Group,

Title:

Body mass index and vigorous physical activity in children and adolescents: an international cross-sectional study.

Date:

2017-08

Citation:

Braithwaite, I. E., Stewart, A. W., Hancox, R. J., Murphy, R., Wall, C. R., Beasley, R., Mitchell, E. A. \& ISAAC Phase Three Study Group, (2017). Body mass index and vigorous physical activity in children and adolescents: an international cross-sectional study.. Acta Paediatr, 106 (8), pp.1323-1330. https://doi.org/10.1111/apa.13903.

Persistent Link:

http://hdl.handle.net/11343/293001 